\title{
The Use of Competition and Creativity as Key Driver to Promote Scientific Culture among Students
}

doi:10.3991/ijet.v5s3.1499

\author{
Alberto Colorni, Susanna Sancassani , Simona Azzali, Nicola Padovani, Alessandra Tomasini \\ Centro METID - Politecnico di Milano, Italy
}

\begin{abstract}
The use of didactic games in order to promote scientific culture leads to innovative methodologies and technologies that can be very effective for the learning process of students or simply to make them more curious about "critical disciplines" such as mathematics. Delivering learning games means making an effort to meet the language and the culture of learners, focusing on their motivation: this aim can be achieved by developing projects and products with a high use of competitiveness and creativity.
\end{abstract}

Index Terms-Serious Games, didactical innovation, creativity learning, scientific culture.

\section{INTRODUCTION}

The development of innovative technological changes is leading to a more effective social inclusion in which every person in being actively involved in the processes of knowledge production and acquisition through interactive activities that may be referred to digital inclusion practices.

In his theory of Multiple Intelligences (Gardner, 1993), Gardner argues the existence of different "frames of mind" (formae mentis) that are present in all people in different extents, according to the specific individual aptitudes. More in details, Gardner describes seven different intelligences: linguistic, logical-mathematical, spatial, bodily-kinesthetic, musical, intrapersonal, interpersonal. The pedagogical approach, proposed by Gardner and the others scientists of multiple formae mentis, argues that effective didactic activities have to put at stake all these different intelligences that are present and not only the linguistic or logical-mathematical ones as usually happens at schools. The use of competition, creativity and new languages, as recreational activities, is for sure coherent with this educational conception, proposing collaborative and symbolic learning processes that involve also the remaining typologies of intelligences.

The pedagogical value of game generally speaking, it has been extensively argued since the past by several studies of educational scientists (Fröbel 1826, Decroly 1921). This conception is based on the idea that childhood owns great expressive and creative capabilities and that education, by means of recreational activities, that often involved positive competitive interaction, is able to motivate young people to learn, involving them in knowledge process that are consistent with their interests and abilities. These kind of activities put at stake imagination and creativity and lead students to actively learn having fun to- gether with their classmates. In this reality, competition, if proposed as further game element a powerful pedagogical device, could raise the quality participation of young people to didactical activities and enable collaborative learning processes in which everyone can give its personal contribution to the construction of knowledge seen as a great social game. Moreover, children and teens own several different languages and codes to express themselves that cannot be identified only with formal linguistic skills (oral and written) if we won't lose them.

The integration of elements that provide competitive and collaboration activities is therefore a key factor on which to invest in the construction of learning courses, mainly because they aim at stimulating the creativity of young people in developing new expressive languages. This is particularly important in the reality in which Centro METID operates: a science university center that aims at supporting the dissemination of scientific knowledge within school. In Italy in particular, the low level of scientific culture among students, as highlighted the OECD PISA 2006 report, is one of the most worrying aspects for which the Government has taken a first step, establishing an interministerial working Group for the development of Scientific and Technological Culture (http://www.pubblica.istruzione.it/argomenti/gst/index.sht $\mathrm{ml}$ ), to suggest the lines of a development policy that defines the duties of public and private subjects, to propose and establish projects and activities addressed to the school system and society as a whole, to suggest, in particular, activities and services for teachers training.

As we will see afterwards, investing on competition and on creativity spur through the use of new languages is particularly successful in engaging and trying to interest in technical and scientific subjects a kind of users (mostly students between 11 and 19 years). From this point of view, it is necessary to pay special attention to the choice of language and format: on one hand the addition of a work load raises the risk of drop-out among the participants, to the other dealing with critical content, generally regarded as hard and heavy, needs to highlight the practical use and to improve pleasantness and involvement aspects.

Formats should be flexible and varied, must integrate different tools and activities, should provide interaction and collaborative learning moments among users, they must leave the traditional books language and be closer to students reality offering new solutions designed to make content and process more engaging and interesting. This is the point at which it is necessary to tie a series of online 
tools that can facilitate the development and dissemination among students. One of the solutions that we have followed to achieve these goals has been to focus on didactic formats mainly based on the logic of competition (or contest) and cooperation: language and tools have been declined in individual or team competitions in single or class rankings, in expert panels and popular juries, in prizes quiz and final awards, all designed to assimilation of concepts, but also the involvement and socialization.

\section{The Use Of GAMES In E-LEARNING PATHS: CASE STUDIES}

The experiences of the projects discussed below, MathOnLine (www.mathonline.it), Performing Galileo (www.performingalileo.net) and La Piazza Virtuale (www.lapiazzavirtuale.it) are joined together by the intention of arousing interest, understanding and passion in technical-scientific subjects through participation in games with educational purposes.

The interactive game and the multimedia web language are two communication channels very close to the world of young people (but not only), around which it is possible to organize learning activities that require content knowledge, creative use of technology, inventiveness and group collaboration. The multidisciplinary context aims at integrating Science, Technology, Theatre and other fields, creating contamination among the different creative areas and facilitating a system approach in exploring knowledge. There are many directions in which it is possible to design this kind of intervention, aimed at guiding young people to science issues in view of an academic future and professional opening:

- interdisciplinary projects of Science and Sports, Science and Music, Science and Arts, Science and Nutrition;

- multiplayer online games mixed to face-to-face activities or events focused on solving specific problems;

- online role-playing games to simulate classical experiments and typical situations;

- e-portfolio of personal learning experiences, works and points of interest emerged as tool for individual guidance.

\section{A. Case Study: MathOnLine Project www.mathonline.it}

The main issue handled 6 years ago in designing MathOnLine learning format was essentially a problem of motivation: how to convince students to attend a course on mathematics, unloved subject, instead of following other more attractive offers? How to convince teachers to use computer, perceived to be highly technical or unnecessarily spectacular, without looking to teach to teach? We have focused on students collaborative work and on a particular language, thought "for them" and based on a mix of cooperation and competition, typical of their daily experience. We tried to develop teachers "learning by doing" method, focusing also on teamwork and (guided) experience exchange.

The learning path is marked out by a competition that takes place at two levels: individual (the classic "all against all", which brings students to give their best to overcome the fellows) and class (the noble "all for one, one for all", which leads them to work together to achieve a common result). Students are assessed on the basis of their preparation in carrying out educational activities, both individual and collaborative, there are moments of self evaluation and verification. Participants are in competition with each other, but at the same time they must help class fellows during the group work: individual and class results, automatically updated, show the names of students at the top positions.

Very strong is the playful role of the avatar and the "virtual prize" which throws the student in the educational game context: for this purpose was created the avatar Ipazia (mathematician lived in the fourth century AD), which is in its virtual life an oracle, observing students and supporting them when needed. Along the way Ipazia asks questions and problems, supports students with suggestions and clarifications, offers them additional knowledge opportunities, sometimes distracts them with anecdotes and curious stories. The oracle can also evaluate: Ipazia's eye blinking and winking means that she is testing the student and the action of the moment becomes important, answering correctly the student is rewarded with new drachmas (old currency into virtual capital), if the answer is wrong drachmas would be subtracted. The exercises (which can be done only once) contribute to the students evaluation. During the year there is also a competition among classes: students of the same class collaborate online with the help of tutors and challenge other classes on a subject related to the modules attended.

The points competition has provided an element of continuity and motivation to participate, registering the highest adhesion in the phases which included interactive online games. The evaluation has created a sophisticated score system, right of promoting competition, without removing important learning elements, such as the accuracy of content, the readiness in finding a solution, the ability to collaborate and solving problems in a creative way. Participants are in competition with each other, but they have also to work in groups to handle with the tasks that each class has to face. Students were assessed and classified according to the preparation shown in the development of individual and collaborative activities and research.

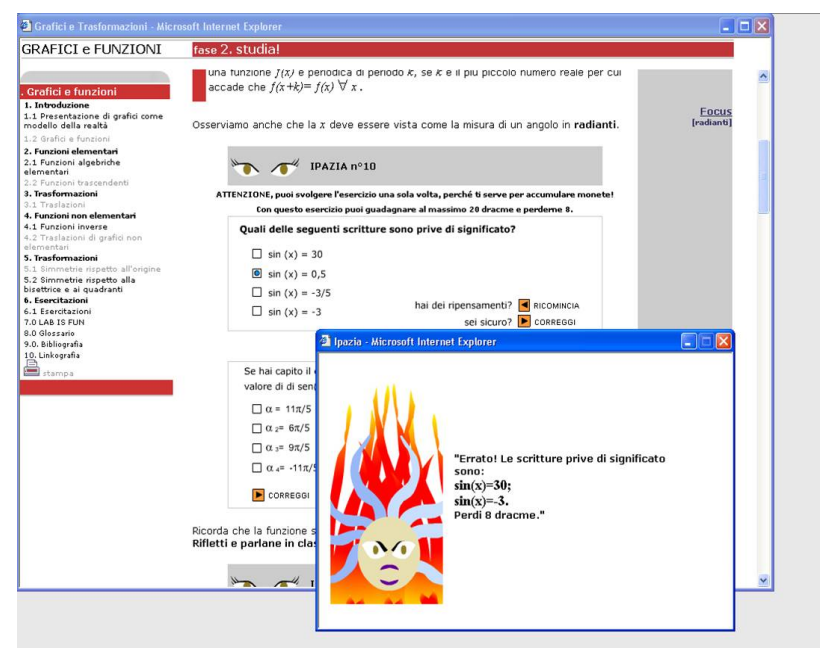

Figure 1. the avatar Ipazia 


\section{B. Case Study: Performing Galileo www.performingalileo.net}

Performing Galileo project was born in 2007/08 by an agreement among Fondazione Tronchetti-Provera, Piccolo Teatro and Politecnico di Milano, in order to test the theatre language as a channel for dissemination of scientific culture.

This project, which lasted about 6 months, has focused on competition among classes of secondary schools to develop multimedia activities on the figure of Galileo Galilei. This was one of the most interesting aspects of the project: a deep integration among different languages, theater and multimedia, closer to young people in the game format of competition.

The project was divided into three phases:

- the performance of Brecht's play "Life of Galileo" dedicated to young people during which students were asked to participate more actively shooting parts of the play, taking photographs, interviewing actors and public. All this material was made available online at the project site to be used in the second phase, in which students has developed their class projects;

- the contest, in which students and their teachers were asked to develop a class project on issues related to the figure of Galileo, using as inspiration materials made available on the wiki. Each group has worked at school in complete autonomy as regards the choice of language and multimedia tools;

- the award day, on the basis of votes obtained by the popular jury (who voted online favorites projects) and by the panel of experts. The works received have been about fourty, many of them really interesting both from technological and content point of view.

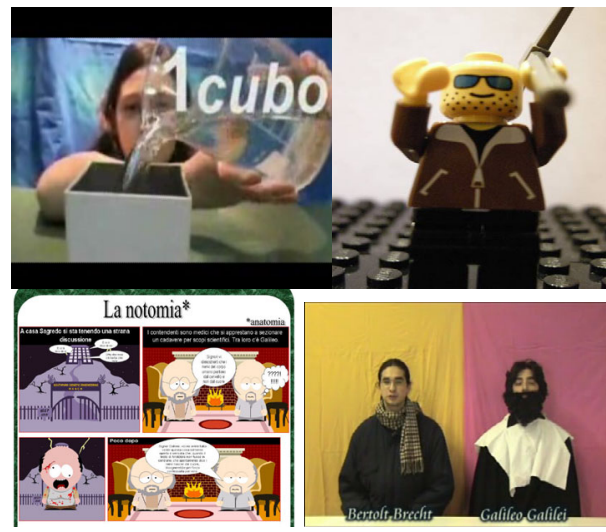

Figure 2. Some of the projects.

\section{Case study: La Piazza Virtuale www.lapiazzavirtuale.it}

This project was created with the purpose to test a learning format to develop and disseminate face-to-face event through web activities. La Scienza in Piazza ${ }^{\circledR}$ is a true itinerant Science Center designed and managed by Fondazione Golinelli, which aims at spreading and disseminating scientific culture among students of all levels, people of all ages so as to bring science to a wider public as possible. The format of La Scienza in Piazza ${ }^{\circledR}$ is based on "learning by doing" method, on involvement of public who becomes the protagonist through direct experimenta- tion in laboratories and interactive stations and comparisons/debates with famous scientists, young researchers, communicators of science.

The same approach was maintained in La Piazza Virtuale: a highly flexible format which can be integrated with different tools and game activities in order to maintain continuity with the face-to-face event. The project was developed following partly the structure of Performing Galileo, with a Before, a During and an After phase inside a Wiki.

- First phase is thought to prepare and encourage public to participate in Scienza in Piazza ${ }^{\circledR}$.

- Second phase is the more structured, providing a "Logbook" open to students who could tell their own experience of scientists, a virtual "Guestbook" to leave their signature or a comment directly from face-to-face event, the" Treasure Hunt " a true challenge on naturalistic issues (for primary school students) and DNA (for secondary school students).

- Third phase provides a contest for all levels classes to produce multimedia works on different themes: for primary and secondary schools on "Science and environment: good and bad examples around you", in high schools "Bioethics, possible and impossible interviews". Teachers and students will be followed during a period of 3 months, in which they will be involved in the development of projects by a continuous updating of the wiki material, multimedia quiz, interviews with experts, etc...

Currently, the third phase is being carried out with about fifteen classes enrolled for the contest. One of most successful activities has been the "Treasure Hunt" where competition had a big weight in the involvement of students.

We note that, more than in other projects, "free" attendance to online activities, not connected to a learning path and to strong and continuous spur, has been quite low.

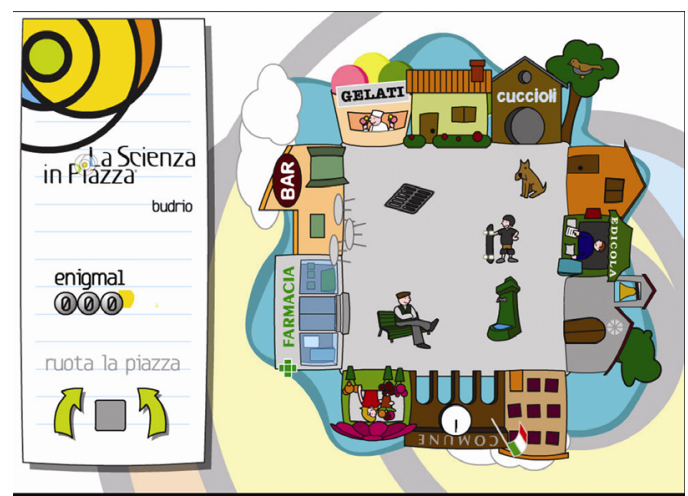

Figure 3. The "Treasure Hunt" and wiki activities

\section{Case Study: LUDUS an international project about} Serious Games - www.serious-gaming.info

The use of games in learning paths is affecting the training policies of companies as well, where Human Resources are starting to look at Serious Games (SG) as a real "tool" to transfer knowledge and skills. Serious Games are generally perceived as games that engage users in their pursuit, and contribute to the achievement of a defined purpose other than pure entertainment. They involve goal orientated 'play', often in real world scenarios 
and intended to 'improve' the player's knowledge, awareness or skills. Most often they are used for corporate training, education, thinking / logic / math skills, simulations, military training, health care, government / management, and social change.

The LUDUS project (www.serious-gaming.info) brings together 8 partners from the South East Europe area, aiming to promote awareness and to create an international network around the topic of Serious Games. The LUDUS Consortium is made of Universities, Regional Development Agencies and Industrial Associations that share knowledge and experiences through innovative tools (web 2.0) and through on-site conferences, seminars and workshops. The main idea is to develop the discussion and interest around SG, collecting materials, resources and activities that can be used as guidelines for potential users and stakeholders.

The international overview provided by the project is allowing METID Centre to look at foreign experiences and at the same time to widespread its expertise about games in learning paths and about e-collaboration processes and tools.

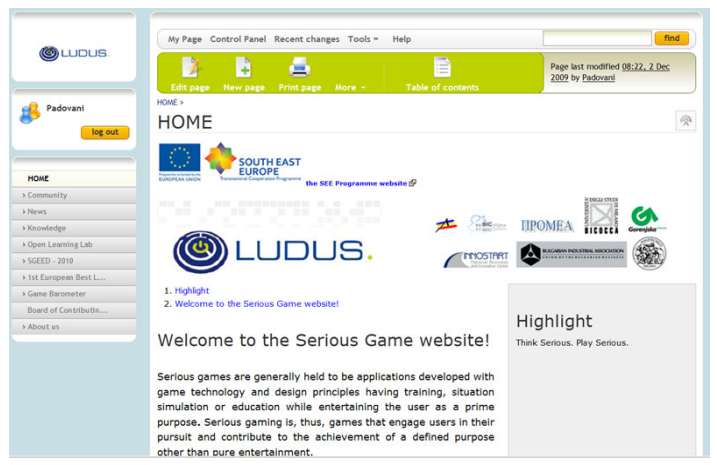

Figure 4. The Home Page of the project

\section{RESULTS}

In the following tables there are some results concerning the projects reported as Case Studies. In some cases the results refers to learning evaluation marks (MathOnLine), in others they refer to attitude toward scientific themes and issues developed after the participation at the project (Performing Galileo).

\section{A. Mathonline}

High school students attending MathOnLine have followed the majority of the online modules delivered (about 4 hours of work a week) in both last editions, though in the 2008/2009 they have been more active, like showed in Tables I and II. In tables III and IV it is reported the success of the students in attending the online modules.

\section{B. Performing Galileo}

After the project a survey has been delivered to students and teachers, aiming to investigate mainly the gap created by the project in the attitude toward Science. The 54,50\% of the teachers claim that the interested toward the discipline that they teach has increased; the 72,70 of students says that they are more curious about scientific issue.

Theatre is considered by the majority of students a proper "media" to widespread the scientific contents (86,40\%), like Internet and Cinema for the $81 ; 80 \%$ and
77,30\%. Students defined Science with three expressions or words that should explain its meaning: research (37,90\%), help evolution $(13,80 \%)$ or innovate $(13,10 \%)$.

TABLE I.

MODULES ATTENDED BY THE STUDENTS OF MATHONLINE 2008/2009

\begin{tabular}{|c|c|c|}
\hline Online Modules participation & Students & $\%$ \\
\hline 4 & 78 & $72 \%$ \\
\hline 3 & 6 & $5,5 \%$ \\
\hline 2 & 8 & $7,5 \%$ \\
\hline 1 & 16 & $15 \%$ \\
\hline
\end{tabular}

TABLE II.

MODULES ATTENDED BY THE STUDENTS OF MATHONLINE 2009/2010

\begin{tabular}{|c|c|c|}
\hline Online Modules participation & Students & $\%$ \\
\hline 4 & 52 & $48,88 \%$ \\
\hline 3 & 8 & $7,52 \%$ \\
\hline 2 & 23 & $21,62 \%$ \\
\hline 1 & 11 & $10,34 \%$ \\
\hline
\end{tabular}

TABLE III.

MODULES ATTENDED WITH SUCCESS (FINALE MARK HIGHER THAN 60/100) BY THE STUDENTS OF MATHONLINE 2008/2009

\begin{tabular}{|c|c|c|}
\hline Online Modules with positive mark & Students & $\mathbf{\%}$ \\
\hline 4 & 57 & $53 \%$ \\
\hline 3 & 18 & $16,5 \%$ \\
\hline 2 & 5 & $4,5 \%$ \\
\hline 1 & 14 & $13 \%$ \\
\hline 0 & 14 & $13 \%$ \\
\hline
\end{tabular}

TABLE IV.

MODULES ATTENDED WITH SUCCESS (FINALE MARK HIGHER THAN 60/100) BY THE STUDENTS OF MATHONLINE 2009/2010

\begin{tabular}{|c|c|c|}
\hline Online Modules with positive mark & Students & $\mathbf{\%}$ \\
\hline 4 & 43 & $40,42 \%$ \\
\hline 3 & 9 & $8,46 \%$ \\
\hline 2 & 10 & $9,40 \%$ \\
\hline 1 & 20 & $18,80 \%$ \\
\hline 0 & 14 & $13,16 \%$ \\
\hline
\end{tabular}

\section{REFERENCES}

[1] Gardner, H. (1993). Multiple Intelligences: The Theory in Practice, Basic Book, New York.

[2] Fröbel, F. (1826). On the Education of Man (Die Menschenerziehung), Keilhau/Leipzig: Wienbrach.

[3] OCSE PISA 2006, Programme for International Student Assessment, http://www.invalsi.it/invalsi/ric.php?page=ocsepisa06.

[4] Decroly, O.; Boon, G. (1921). Vers l'école rénovée: une première étape, Office de Publicité; F. Nathan.

[5] Brambilla. F.; Colorni, A, ; Padovani, N. (2008) Coaching didattico, matematica, teatro: strumenti online per la diffusione della conoscenza scientifica, in $\mathrm{V}^{\wedge}$ Congresso SIeL, Trento 8 - 11 October 2008.

[6] MathOnLine, http://www.mathonline.it

[7] Performing Galileo, http://www.performingalileo.net

[8] Scienza in Piazza, http://www.lascienzainpiazza.it

\section{AuTHORS}

Alberto Colorni, Susanna Sancassani , Simona Azzali, Nicola Padovani, Alessandra Tomasini are with Centro METID - Politecnico di Milano, Italy.

This paper is an extended version of a presentation given during the "Creative Learning with Serious Games" workshop during the "Fun and Games 2010" conference in Leuwen on 15 September 2010, and was supported by the e-VITA European Life Experiences", project nr 143526-LLP-1-2008-1-IT-KA3-KA3MP.

Submitted October $31^{\text {st }}$, 2010. Published as resubmitted by the authors November $11^{\text {th }}, 2010$. 